\title{
Mammary Paget's disease without underlying malignancy of the breast
}

\author{
Nuri Jang ${ }^{1}$, Suhwan Kang ${ }^{2}$, Young Kyung Bae ${ }^{1}$ \\ Departments of ${ }^{1}$ Pathology and ${ }^{2}$ General Surgery, Yeungnam University College of Medicine, Daegu, Korea
}

Mammary Paget's disease (MPD) is usually accompanied by underlying breast malignancy; however, a few cases have been reported as only skin lesions without any evidence of malignancy of the breast on imaging tests and microscopic examination of surgical specimen. Here, we describe a 47-year-old woman who visited our hospital who had an eczematous lesion on right nipple and areola for over 10 years. The lesion was diagnosed as Paget's disease by punch biopsy; however, imaging studies demonstrated no breast malignancy or lymph node metastasis. The patient underwent surgery of on the nipple and areola including underlying breast tissue. No underlying malignancy was found upon microscopic examination, except for Paget's disease. Immunohistochemical stains revealed that the tumor cells were positive for cytokeratin 7 , and negativity for p63, cytokeratin 5/6, estrogen receptor, progesterone receptor, and human epidermal growth factor receptor 2. We report a case of MPD without underlying malignancy. To the best of our knowledge, this is the third case reported in Korea.

Keywords: Paget's disease; Breast; Immunohistochemistry

\section{INTRODUCTION}

Paget's disease is an intraepithelial adenocarcinoma that can occur both in the breast and in the extramammary anogenital skin. Mammary Paget's disease (MPD) is an uncommon breast cancer that is usually associated with underlying malignancy of the breast. Only a few cases of MPD without underlying malignancy of the breast have been reported in English literature [1-9]. We report a case of Paget's disease in a 47year-old woman who did not have any clinical or pathological evidence of underlying malignancy in breast parenchyma. To the best of our knowledge, this is the third case in Korea.

Received: June 28 2017, Revised: August 8, 2017 Accepted: August 29, 2017

Corresponding Author: Young Kyung Bae, Department of Pathology, Yeungnam University College of Medicine, 170, Hyeonchung-ro, Nam-gu, Daegu 42415, Korea Tel: +82-53-640-6755, Fax: +82-53-622-8432

E-mail: ykbae@ynu.ac.kr

\section{CASE}

A 47-year-old woman presenting erythematous patches on the right nipple and areola (Fig. 1) visited the department of

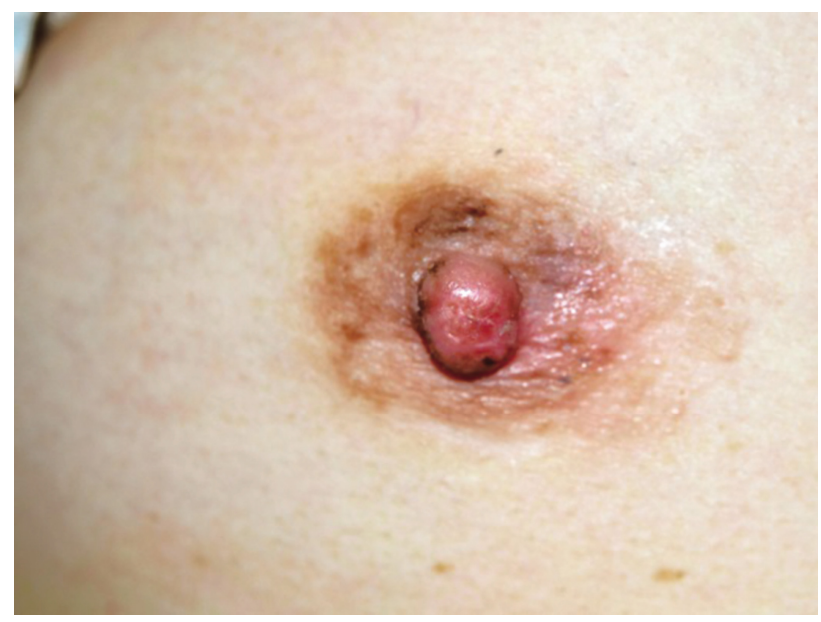

Fig. 1. Gross finding of right nipple and areola. The areolar skin is erythematous and the nipple has no ulcer.

Copyright $($ C) 2018 Yeungnam University College of Medicine

This is an Open Access article distributed under the terms of the Creative Commons Attribution Non-Commercial License (http://creativecommons.org/licenses/by-nc/4.0/) which permits unrestricted non-commercial use, distribution, and reproduction in any medium, provided the original work is properly cited. 
dermatology at our hospital. The lesion had been present for 10 years with repeated improvement and deterioration. The patient had taken only conservative treatment without any further evaluation in local clinics. Based on punch biopsies of the nipple and areola, the lesions were diagnosed as Paget's disease. Immunohistochemical (IHC) stains were performed and the results in tumor cells were as follows: cytokeratin $7(+)$; p63 (-); cytokeratin 5/6 (-).

Consecutively conducted mammography and ultrasonography demonstrated heterogeneous dense breast tissue and several small, oval shaped hypoechoic nodules in the bilateral breast, which indicated benign lesions (Fig. 2A, 2B). Positron emission tomography-magnetic resonance imaging revealed a thin enhancing lesion $(1.0 \times 0.4 \mathrm{~cm})$ on the nipple and areola of the right breast, but there was no evidence of regional lymph node metastasis or distant metastasis. The patient underwent breast-conserving surgery of the nipple and areolar skin with sentinel lymph node biopsy.

The resected right breast measured $24.2 \mathrm{~g}$, and was $5.4 \times$ $4.7 \times 2.1 \mathrm{~cm}$ in size. The overlying skin measured $4.0 \times 2.5 \mathrm{~cm}$ and the nipple measured $1.5 \times 1.3 \mathrm{~cm}$. The skin contained a $3.5 \times 2.3 \mathrm{~cm}$ light red discoloration patch and the nipple was relatively smooth on the surface, except for a previous biopsy site (Fig. 3A). There was no definite mass-like lesion in the breast parenchyma on serial sections (Fig. 3B).

Microscopically, large atypical tumor cells were arranged in
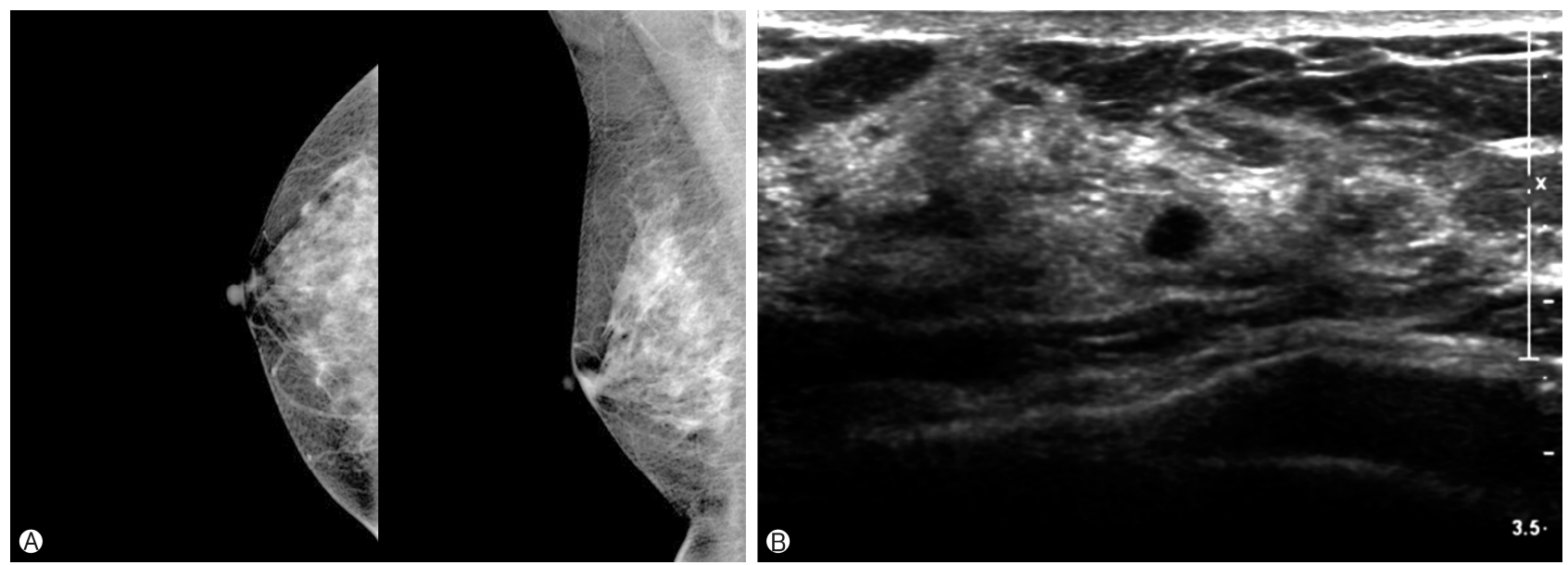

Fig. 2. Radiologic findings of the breast. (A) Mammography showed unremarkable finding. (B) Ultrasonography demonstrated a 0.4cm-sized hypoechoic lesion suggesting benign.

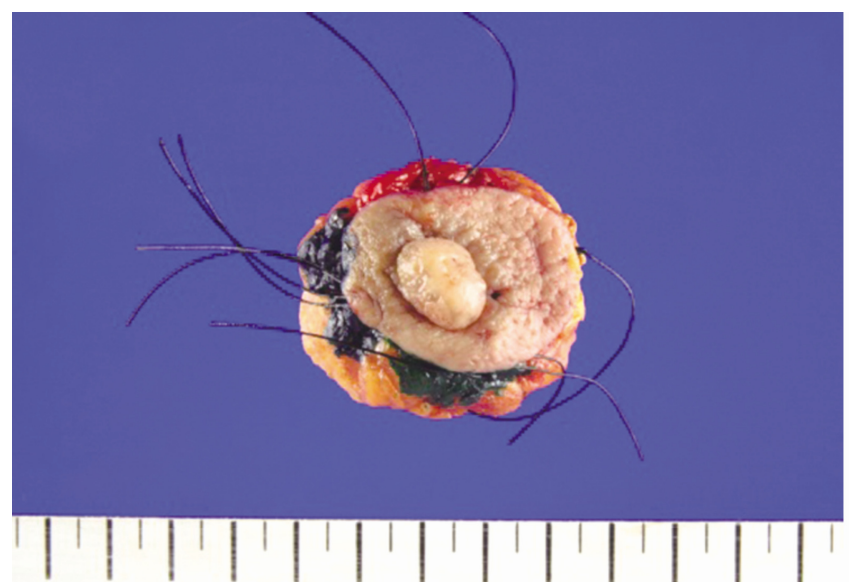

(A)

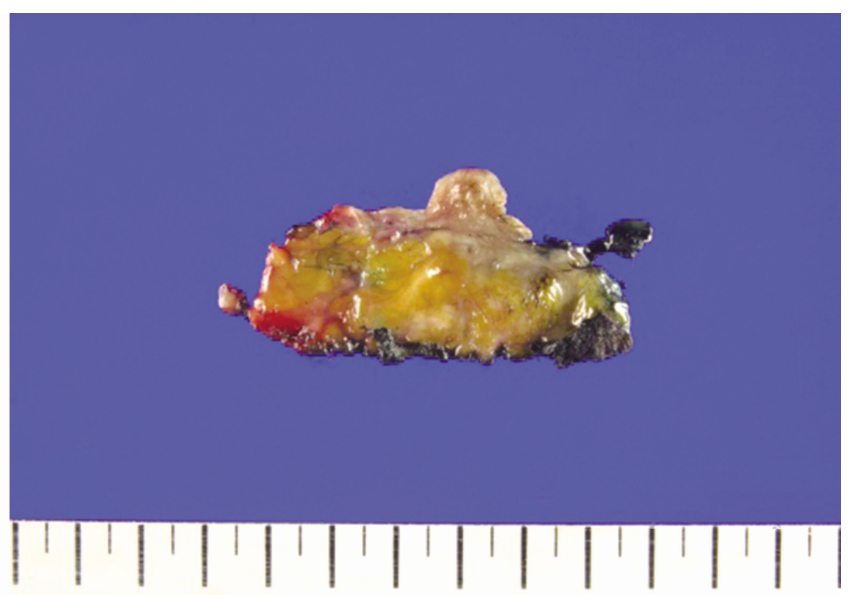

(B)

Fig. 3. Gross findings of the resected specimen. (A) The skin showed slightly light red discoloration. (B) On section, there was no definite mass-like lesion. 
glandular clusters, or small nests within the epidermis. These had abundant basophilic and fine granular cytoplasm with nuclear atypia and pleomorphism. Some tumor cells contained intracytoplasmic mucin. The tumor cells were confined to the epidermis, and no involvement of the lactiferous duct or breast parenchyma by carcinoma was identified. On IHC staining, tumor cells were negative for estrogen receptor (ER), progesterone receptor (PR), human epidermal growth factor receptor 2 (HER2), CDX-2, mucin 2 (MUC2) and mucin 5AC (MUC5AC), but positive for MUC1.

\section{DISCUSSION}

MPD, which was first described by James Paget in 1874, is usually accompanied by underlying breast malignancy (8595\%), mostly high-grade invasive carcinoma, with no special type or ductal carcinoma in situ [10,11]. MPD without underlying carcinoma is very rare, accounting for $1.4-13 \%$ of all MPD $[7,12,13]$. Sometimes, MPD occurs by pagetoid spread of ductal carcinoma in situ originating from the lactiferous ducts of breast to the epidermis of the nipple. However, it has been suggested that primary MPD can originate from ad- nexal glands, Toker cells, or pluripotent stem cells within the epidermis, rather than from the lactiferous ducts. Secondary MPD indicates the spread of tumor cells from underlying breast carcinoma.

Previous studies analyzed IHC features of primary and secondary MPD and extramammary Paget's disease (EMPD) [14]. However, it is impossible to distinguish primary from secondary MPD using IHC stains. Interestingly, the results of IHC for HER2 protein showed distinct patterns between MPD and EMPD. HER2 positivity was more commonly observed in MPD (71-100\%), but less frequently detected in EMPD (0-55\%), which also showed weaker staining for HER2 than the former. Our case represented complete negative immunoreactivity for HER2 (Fig. 4F). The immunostaining results for ER and PR were also negative (Fig. 4D, 4E).

Meissner et al. analyzed HER2 expression in MPD with or without underlying breast carcinoma and in EMPD [15]. In their study, all five MPD cases without underlying malignancy showed positive expression for HER2, similar to the cases of MPD with underlying breast cancer. These findings suggested that the development of MPD and HER2 positive breast carcinoma have common cytogenetic alterations or signaling
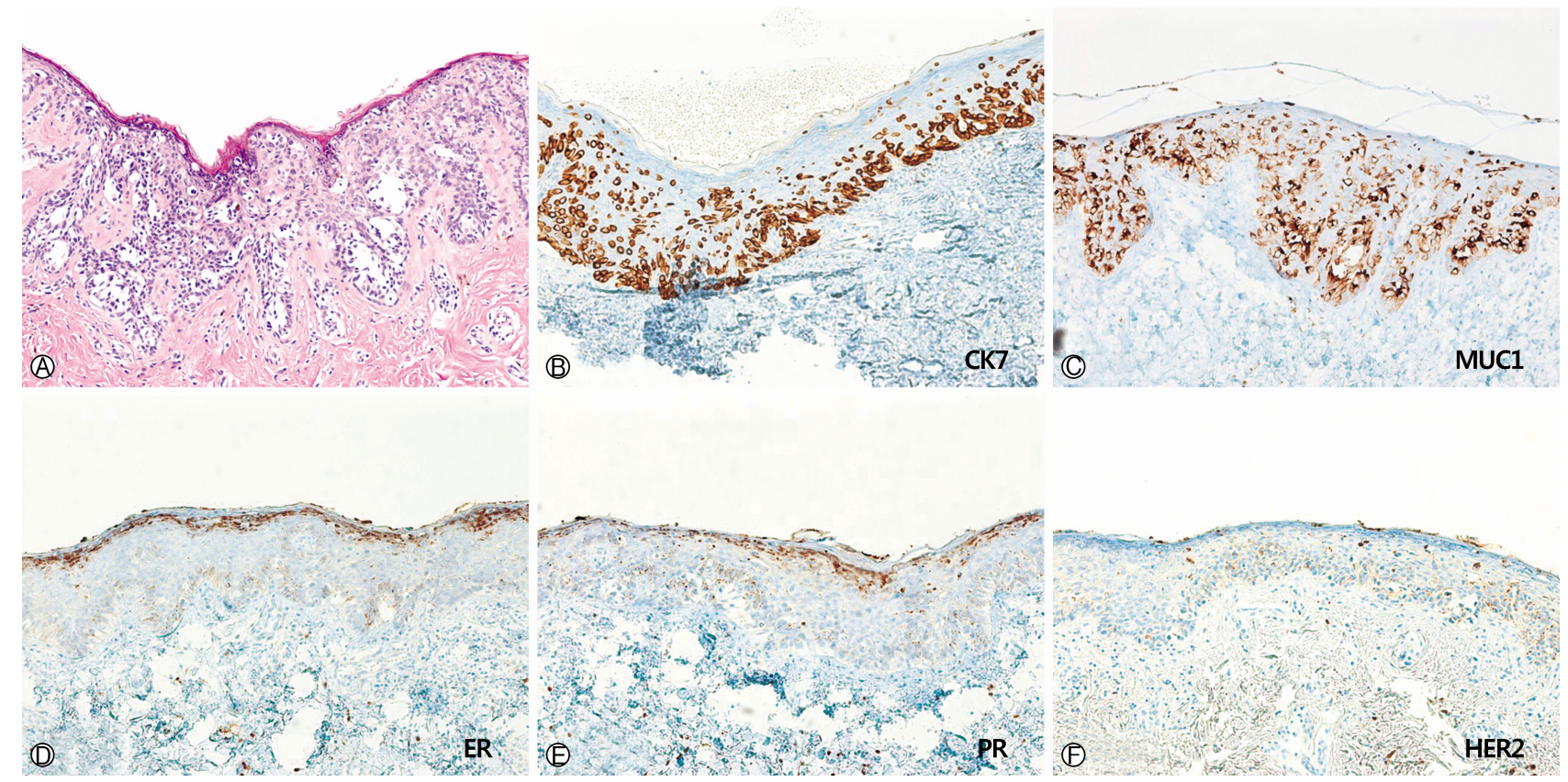

Fig. 4. Microscopic findings of the nipple and areola. (A) The tumor cells formed nests or showed glandular differentiation within the epidermis. Some of single tumor cells are spreading to the striata (H\&E stain, $\times 200)$. (B, C) The tumor cells were positive for CK7 and MUC1 (B, ×200; C, ×200). (D-F) The tumor cells were negative for ER, PR, and HER2 (D, ×100; E, ×100; F, ×100). CK7, cytokeratin 7, MUC1, mucin 1, ER, estrogen receptor, PR, progesterone receptor, HER2, human epidermal growth factor receptor 2. 
pathways associated with tumorigenesis.

Liu et al. reported that MPD and EMPD are different biological diseases despite their morphological similarity [16]. They evaluated the expression of HER2 and their downstream signaling pathway members, including AKT/pAKT and phosphatase and tensin homologue (PTEN) in MPD and EMPD. They found that HER2 overexpression was more frequent in MPD than in EMPD, and that HER2 negativity associated with AKT and PTEN positivity was present only in EMPD.

Different mucin expression patterns have been reported in MPD and EMPD. Kuan et al. conducted IHC staining of MUC series in 13 cases of MPD and 13 cases of EMPD [17]. MUC1 was generally positive in both MPD and EMPD. In contrast, MUC5AC was negative in all MPD cases, but positive in 10 out of 13 cases of EMPD. Liegl et al. also demonstrated that MUC5AC immunostaining between MPD and EMPD was quite different, as positive staining for MUC5AC was $0 \%$ in MPD (0/50), but $42.1 \%(8 / 19)$ in EMPD [14]. In our case, tumor cells were strongly positive for MUC1, but negative for MUC5AC. And it is exclusive of Paget's disease of extramammary origin, such as metastatic adenocarcinoma from gastrointestinal tract because the tumor cells showed negative immunostaining for CDX-2 and MUC2.

There have been about 20 cases of MPD without underlying breast carcinoma [1-9]. Prognosis of MPD is different depending on whether it is associated with underlying breast carcinoma or not. MPD patients with underlying breast malignancy have poorer prognosis than those without a palpable breast tumor (5-year survival rate, $32-43 \%$ vs. 92-94\%) [18].

In Korea, two cases of MPD without underlying malignancy of breast have been reported. The first case was reported by Han et al. in 1976 [19]. The patient underwent radical mastectomy and was diagnosed as with Paget's disease, but did not have any underlying malignancy in breast parenchyma. The second case was reported by Yeo et al. in 1994 [20]. They collected fifteen cases of MPD, including three cases of MPD showing only nipple change, but malignancy of breast parenchyma. Among these, one case had no malignant lesions and the other two cases had invasive carcinoma and intraductal carcinoma, respectively. The follow-up data of each case were not described in those reports.

In our case, the patient was alive without any clinical evidence of recurrence for 8 months after surgery. She also has no malignancies in other organs. We report here the third case of MPD without underlying malignancy of the breast in Korea.

\section{CONFLICT OF INTEREST}

No potential conflict of interest relevant to this article was reported.

\section{ORCID}

Nuri Jang, https://orcid.org/0000-0001-7182-964X

Young Kyung Bae, https://orcid.org/0000-0002-6689-9413

\section{REFERENCES}

1. Haagensen CD. The physiology of the breast as it concerns the clinician. Am J Obstet Gynecol 1971;109:206-9.

2. Lagios MD, Westdahl PR, Rose MR, Concannon S. Paget's disease of the nipple. Alternative management in cases without or with minimal extent of underlying breast carcinoma. Cancer 1984;54:545-51.

3. Jones RE Jr. Mammary Paget's disease without underlying carcinoma. Am J Dermatopathol 1985;7:361-5.

4. Campana F, Vielh P, Fourquet A, Schlienger P, Jullien D, Durand JC, et al. Paget's disease of the nipple without any associated mammary tumor clinically or radiologically detectable. Apropos of 51 cases treated at the Curie Institute. J Gynecol Obstet Biol Reprod (Paris) 1987;16:1069-73.

5. Mori O, Hachisuka H, Nakano S, Maeyama Y, Sasai Y. A case of mammary Paget's disease without an underlying carcinoma: microscopic analysis of the DNA content in Paget cells. J Dermatol 1994;21:160-5.

6. Pranteda G, Gueli N, Bottoni U, Pranteda G, Calvieri S. Mammary Paget's disease with acantholytic features and without any detectable breast tumor. J Exp Clin Cancer Res 1998;17: 519-22.

7. Caliskan M, Gatti G, Sosnovskikh I, Rotmensz N, Botteri E, Musmeci S, et al. Paget's disease of the breast: the experience of the European Institute of Oncology and review of the literature. Breast Cancer Res Treat 2008;112:513-21.

8. Lim HS, Jeong SJ, Lee JS, Park MH, Kim JW, Shin SS, et al. Paget disease of the breast: mammographic, US, and MR imaging findings with pathologic correlation. Radiographics 2011;31:1973-87.

9. Bansal S, Sahoo B, Agarwal P, Garg VK, Rao S. A rare presentation of mammary Paget's disease involving the entire breast in the absence of any underlying ductal malignancy. Indian J Dermatol Venereol Leprol 2013;79:518-21.

10. Lloyd J, Flanagan AM. Mammary and extramammary Paget's disease. J Clin Pathol 2000;53:742-9.

11. Dalberg K, Hellborg H, Wärnberg F. Paget's disease of the nipple in a population based cohort. Breast Cancer Res Treat 2008;111:313-9. 
12. Chen CY, Sun LM, Anderson BO. Paget disease of the breast: changing patterns of incidence, clinical presentation, and treatment in the U.S. Cancer 2006;107:1448-58.

13. Siponen E, Hukkinen K, Heikkilä P, Joensuu H, Leidenius M. Surgical treatment in Paget's disease of the breast. Am J Surg 2010;200:241-6.

14. Liegl B, Leibl S, Gogg-Kamerer M, Tessaro B, Horn LC, Moinfar F. Mammary and extramammary Paget's disease: an immunohistochemical study of 83 cases. Histopathology 2007; 50:439-47.

15. Meissner K, Rivière A, Haupt G, Löning T. Study of neu-protein expression in mammary Paget's disease with and without underlying breast carcinoma and in extramammary Paget's disease. Am J Pathol 1990;137:1305-9.

16. Liu W, Iqbal J, Khoury T. Mammary Paget's disease and extra- mammary Paget's disease: two morphologically similar but biologically different diseases. J Cutan Pathol 2010;37:1145-9.

17. Kuan SF, Montag AG, Hart J, Krausz T, Recant W. Differential expression of mucin genes in mammary and extramammary Paget's disease. Am J Surg Pathol 2001;25:1469-77.

18. Ling H, Hu X, Xu XI, Liu ZB, Shao ZM. Patients with nipple-areola Paget's disease and underlying invasive breast carcinoma have very poor survival: a matched cohort study. PLoS One 2013;8:e61455.

19. Han JY, Hahm JH, Kook HI. Two cases of Paget's disease. Korean J Dermatol 1976;14:255-60. Korean.

20. Yeo JY, Jung SS, Kim BK, Kim IM, Kim IC. Clinical observations on Paget's disease of the breast. J Korean Surg Soc 1994;47:366-73. Korean. 